\title{
CXCR1/2 pathways in paclitaxel-induced neuropathic pain
}

\author{
Brandolini Laura ${ }^{1, *}$, Benedetti Elisabetta ${ }^{2, *}$, Ruffini Pier Adelchi ${ }^{3}$, Russo Roberto ${ }^{4}$, \\ Cristiano Loredana ${ }^{2}$, Antonosante Andrea ${ }^{2}$, d'Angelo Michele ${ }^{2}$, Castelli Vanessa ${ }^{2}$, \\ Giordano Antonio ${ }^{5,6}$, Allegretti Marcello ${ }^{1}$, Cimini Annamaria ${ }^{2,6,7}$ \\ ${ }^{1}$ Dompé Farmaceutici SpA, Via Campo di Pile, L'Aquila, Italy \\ ${ }^{2}$ Department of Life, Health and Environmental Sciences, University of L'Aquila, Italy \\ ${ }^{3}$ Dompé Farmaceutici SpA, Via Santa Lucia, Milano, Italy \\ ${ }^{4}$ Department of Pharmacy, University of Naples Federico II, Italy \\ ${ }^{5}$ Department of Medicine, Surgery and Neuroscience, University of Siena, Siena, Italy \\ ${ }^{6}$ Sbarro Institute for Cancer Research and Molecular Medicine and Center for Biotechnology, Temple University, \\ Philadelphia, USA \\ ${ }^{7}$ National Institute for Nuclear Physics (INFN), Gran Sasso National Laboratory (LNGS), Assergi, Italy \\ "These authors contributed equally to this work
}

Correspondence to: Allegretti Marcello, email: marcello.allegretti@dompe.com

Keywords: chronic pain, chemotherapy, microtubules, IL-8, CXCR1/2 inhibitor

Received: January 04, 2017

Accepted: February 08, 2017

Published: February 20, 2017

\section{ABSTRACT}

Chemotherapy-induced peripheral neuropathy (CIPN) is a type of neuropathic pain that represents a frequent and serious consequence of chemotherapy agents. Over the last years, significant progress has been achieved in elucidating the underlying pathogenesis of CIPN. The interference of taxanes with microtubule has been proposed as a mechanism that leads to altered axonal transport and to permanent neurological damages. The inflammatory process activated by chemotherapeutic agents has been considered as a potential trigger of nociceptive process in CIPN.

In this study we investigated the effect of reparixin, an inhibitor of CXCR1/ CXCR2, in suppressing the development of paclitaxel-induced nociception in rats. Moreover, reparixin activity in reversing the neurotoxic effects induced by paclitaxel or GRO/KC in F11 cells was also analyzed.

Reparixin administered by continuous infusion ameliorated paclitaxel-induced mechanical and cold allodynia in rats. In F11 cells, reparixin was able to inhibit the increase of acetyladed a-tubulin induced both by paclitaxel and GRO/KC. The subsequent experiments were performed in order to dissect the signal transduction pathways under GRO/KC control, eventually modulated by paclitaxel and/or reparixin. To this aim we found that reparixin significantly counteracted p-FAK, p-JAK2/p-STAT3, and PI3K-p-cortactin activation induced either by paclitaxel or GRO/KC.

Overall the present results have identified IL-8/CXCR1/2 pathway as a mechanism involved in paclitaxel-induced peripheral neuropathy. In particular, the obtained data suggest that the inhibition of CXCR1/2 combined with standard taxane therapy, in addition to potentiating the taxane anti-tumor activity can reduce chemotherapyinduced neurotoxicity, thus giving some insight for the development of novel treatments.

\section{INTRODUCTION}

Chemotherapy-induced peripheral neuropathy (CIPN) is a common and potentially disabling side effect of many anticancer drugs [1]. The most frequent symptoms are pain, numbness, or tingling in the hands or feet [1-2]. In a recent meta-analysis of several studies involving 4179 patients on various chemotherapeutic regimens, the prevalence of CIPN was $68.1 \%$ within the first month of treatment, $60.0 \%$ at 3 months, and $30.0 \%$ 
at 6 months [3]. With such a high prevalence of disease, CIPN has important clinical implications significantly impacting the quality of life and often resulting in treatment discontinuation, which may ultimately affect overall survival $[4,2]$. Despite the intensive research dedicated to the identification of therapeutic options able to prevent or treat CIPN [5], the medical need remains very high.

The pathogenesis of CIPN has not been fully elucidated but it is noteworthy that the overall neuropathy symptom profile appears to be substantially shared across different classes of chemotherapeutic agents including taxanes, platinum, proteasome inhibitors, and vinca-alkaloids. Peripheral nerve degeneration or small fiber neuropathy is generally accepted as the underlying mechanism in the development of CIPN [6-7] but several studies point out that neuropathic pain caused by anticancer agents may occur early after the first infusion in the absence of damage to intra-epidermal nerve fibers or axonal degeneration in peripheral nerves [8-9].

Microtubule-stabilizing agents (MTSAs), including taxanes, are effective chemotherapeutic agents for the treatment of many oncologic conditions [10]. Although it is clear that chemotherapeutic agents that damage microtubules, interrupt mitochondrial function, or directly target DNA may affect the integrity and functionality of axons thus leading to peripheral nerve degeneration, several preclinical and clinical evidences concur to suggest a common physio-pathological mechanism partially independent from the antineoplastic drug molecular target.

The inflammatory process activated by chemotherapeutic agents has been considered a potential trigger of the nociceptive process in CIPN [11-12] and the chemotherapy-driven release of proinflammatory and chemotactic cytokines (chemokines) has been identified as one of the primary mechanisms regulating the neuroimmune communication.

Chemotherapeutic exposure consistently induces production and release of pro-inflammatory cytokines such as TNF- $\alpha$, IL-1 $\beta$, IL-6 and chemokines such as IL-8 and MCP-1 [13-15].

Pro-inflammatory cytokines can contribute to neural damage not only by activating the inflammatory process but also by a direct receptor-mediated activity on neurons and glial cells [16-20]. Among the chemokines, Il- 8 and its receptors CXCR $1 / 2$ have been shown to be upregulated in several animal models following nerve injury and implicated in the development and maintenance of neuropathic pain and of the inflammatory hypernociception [21-22].

Interestingly, in a recent controlled study in patients with painful peripheral neuropathy, IL-6 and IL-8 gene expression were found significantly up-regulated in the affected skin biopsies [23] prompting a strong interest on these mediators as potential pharmacological targets for pain management.
The chemokine effects on pain sensation are complex and additional effort is required to clarify the role of these mediators in cancer derived algesia; only the identification of potent and selective chemokine clinical grade inhibitors will allow to fully understand the therapeutic potential of this approach.

Reparixin is an investigational, non-competitive allosteric inhibitor of the IL-8 receptors CXCR1 and CXCR2 [24] and it has been investigated as a potential novel antineoplastic agent in synergy with standard chemotherapy targeting the $\mathrm{CXCR} 1^{+}$breast cancer stem population [25-27]. In a recently completed phase Ib trial in metastatic breast cancer, the safety, pharmacokinetics and antitumor activity of reparixin in combination with weekly paclitaxel were investigated. In this study we observed a sizeable response rate with a low incidence and severity of peripheral neuropathy, suggesting that neurological toxicity, but not antitumor activity, may be reduced by reparixin administration [26].

In this paper we put to test for the first time the hypothesis that inhibition of IL-8 signaling could attenuate the development of chemotherapy induced neurotoxicity.

On these bases, this work aimed to clarify the effect of paclitaxel on CXCR1-CXCR2 dependent pathways in neuropathic pain and to elucidate the effect of a known CXCR1-CXCR2 inhibitor, reparixin, in counteracting neuropathic pain behavior and biomarkers in the CIPN context.

\section{RESULTS}

\section{In vivo model: effect of reparixin in paclitaxel- induced mechanical and cold allodynia}

In control animals administered with paclitaxel vehicle i.p., the paw withdrawal threshold remained unchanged during the whole experimental period, with a trend corresponding to that achieved in naïve animals with received no treatment (data not shown). In contrast, paclitaxel-saline -treated animals showed marked changes in paw withdrawal responses, which are prominently displayed at 5 days after the first paclitaxel treatment (the first time point observation after paclitaxel injection) and persisted at least 2 weeks (Figure 1A).

In particular, in DPA test, paw withdrawal threshold of paclitaxel-saline-treated animals resulted significantly reduced at day 5, 7, 10 and 14 (Figure 1A). Similarly, in cold allodynia experiments, no paw withdrawal response was induced by acetone in control animals, indicating that acetone-evoked cold stimulation is not noxious in non neurophatic rats. On the other hand, the numbers of paw withdrawal threshold resulted significantly increased at days 5, 7, 10 and 14, in paclitaxel-saline-treated animals (Figure 1B).

Reparixin antinociceptive effect was visible over the time-course corresponding to drug delivery by micro- 
osmotic pump; conversely, the activity disappeared after the end of drug delivery by pump (day 11), indicating that the observed protection is strictly correlated to drug administration and action.

In fact, continuous infusion of reparixin $(8 \mathrm{mg} / \mathrm{hr} / \mathrm{kg})$ was able to reduce in a significant way, paclitaxel-evoked mechanical allodynia at days $5(P<0.01), 7(P<0.001)$, and $10(P<0.001)$, whereas no activity was determined at day 14, three days after the end of drug delivery (Figure 1A).

Likewise, animals treated with reparixin showed a significant reduction of cold allodynia at days $5(P<0.01)$, $7(P<0.001)$, and $10(P<0.001)$, whereas, no activity was determined at day 14 , three days after the end of drug delivery (Figure 1B).

\section{In vitro models}

The viability assay under the different treatments (Figure 2A) shows that paclitaxel, in the concentrationrange of 5-20 $\mathrm{nM}$, and reparixin, in the concentration range of $5-20 \mu \mathrm{M}$ were ineffective in modulating cells viability.

For all the other experiments, reparixin was used at the final concentration of $10 \mu \mathrm{M}$ and paclitaxel at the final concentration of $10 \mathrm{nM}$.

In Figure 2B, control (not treated), paclitaxel and reparixin treated neurons probed for anti-acetylated $\alpha$-tubulin (markers of stable microtubules) are shown. In control cells, acetylated $\alpha$-tubulin appears moderately present; a similar situation is found in cells treated with reparixin. In paclitaxel-treated neurons, in agreement with the literature [28], increased acetylated $\alpha$-tubulin is observed. In fact, the fluorescence intensity in neurites appears more intense and an increase of neurite diameter and cytoskeleton organization is apparent. Acetylated $\alpha$-tubulin in paclitaxel+reparixin-treated neurons appears similar to that of control conditions, thus indicating that reparixin presence counteracts paclitaxel effects.

Acetylated $\alpha$-tubulin was assayed also by western blotting analysis. In Figure 2C, the western blotting and densitometric analyses for this marker are reported. In agreement with the morphological data, paclitaxel determines a significant increase of acetylated $\alpha$-tubulin, while under combined treatments the protein appears at the same level of control cells. In order to determine whether the observed effects may be triggered by the CXCR2 natural ligand, GRO/KC, which is thought to play a role in the rat similar to that played by IL-8 in humans, was used. Acetylated $\alpha$-tubulin was re-assayed by western blotting under $\mathrm{GRO} / \mathrm{KC}$ treatment at different concentrations (Figure 2D), and compared to paclitaxel treatment. It is possible to observe that $\mathrm{GRO} / \mathrm{KC}$ is able to increase acetylated $\alpha$-tubulin at each concentration used.

The subsequent experiments were performed in order to dissect the signal transduction pathways, under GRO/KC control, eventually modulated by paclitaxel and/or reparixin (Figure 3). To this purpose the first enzyme studied was the active form of the protein of fokal adhesion, p-FAK. The protein is significantly increased by paclitaxel treatment, while under combined treatments it appears at the same level of control cells (Figure 3A).

In control and treated cells, the localization for the cytoskeletal component actin (Figure 3B) and the SEM analysis (Figure 3C) were also performed. By the mean of actin localization also neurite thickness (Figure 3D) was calculated. It is possible to observe that under paclitaxel treatment, neurites appear with a greater thickness than control cells. Under combined treatment cells appear as control ones.

The other enzyme of CXCR1/CXCR2 pathway studied was the active form of the JAK2 protein, involved in the p-STAT3 signaling (Figure 4A), which in turn is
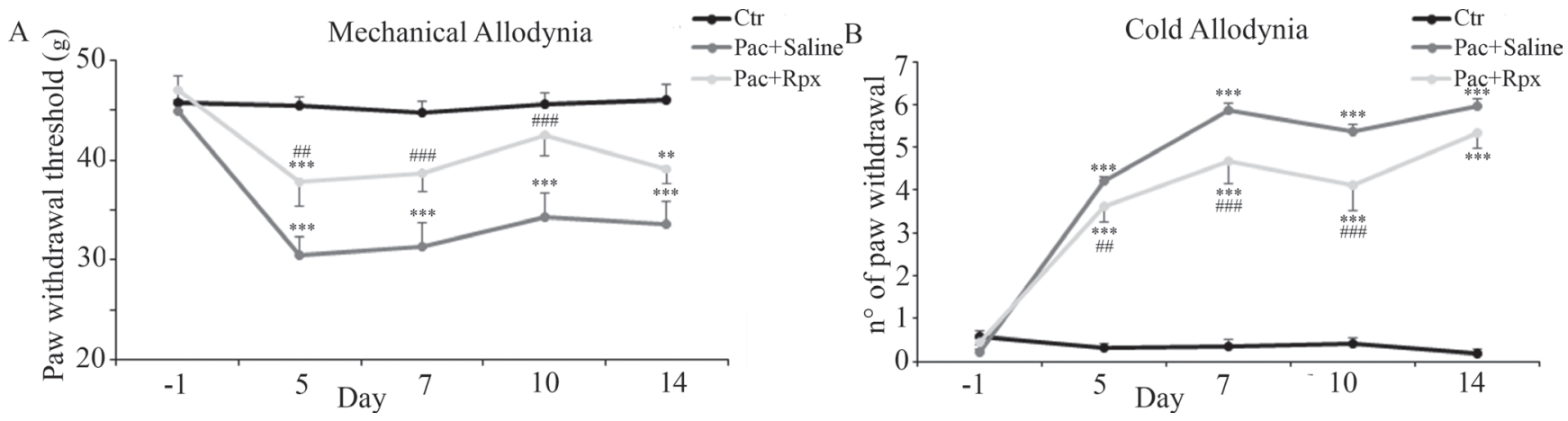

Figure 1: Effect of reparixin on paclitaxel-induced mechanical and cold allodynia: In control animals administered with paclitaxel vehicle i.p. (Ctr, black dots) the paw withdrawal responses remained unchanged during the whole experimental period (panel A and B). Rats treated with paclitaxel + pumps filled with saline (Pac+Saline, gray dots), showed marked changes in paw withdrawal responses (panel A and B). Continuous infusion of reparixin (Pac+Rpx, light gray dots) was able to reduce in a significant way, paclitaxelevoked mechanical (panel A) and cold (panel B) allodynia at days 5, 7 and 10, whereas no activity was determined on day 14, three days after the end of drug delivery. Data are shown as mean $\pm \mathrm{SE}$ of 10 animals per group. ${ }^{* * *} P<0.001$, and $* * P<0.01$ vs the respective Ctr group; ${ }^{\# \#} P<0.001$ and ${ }^{\# \#} P<0.01$ vs the respective Pac+Saline group. 
involved in neuropathic pain and synaptic plasticity [29-30]. It is possible to observe that paclitaxel increases p-JAK2, while the presence of reparixin restores the control conditions. In the same Figure 4B, p-STAT3 levels, under the different conditions, are reported. Paclitaxel increases p-STAT3 levels, with respect to control, while reparixin counteracts this effect.

Finally, PI3K-p-cortactin pathway, which is involved in axonal arborization and synaptic plasticity, appears strongly up-regulated by paclitaxel, while the presence of reparixin counteracts also this effect (Figure 4C and 4D).

With the aim to clarify the correlation between paclitaxel effects and GRO/KC effects, F11 cells were

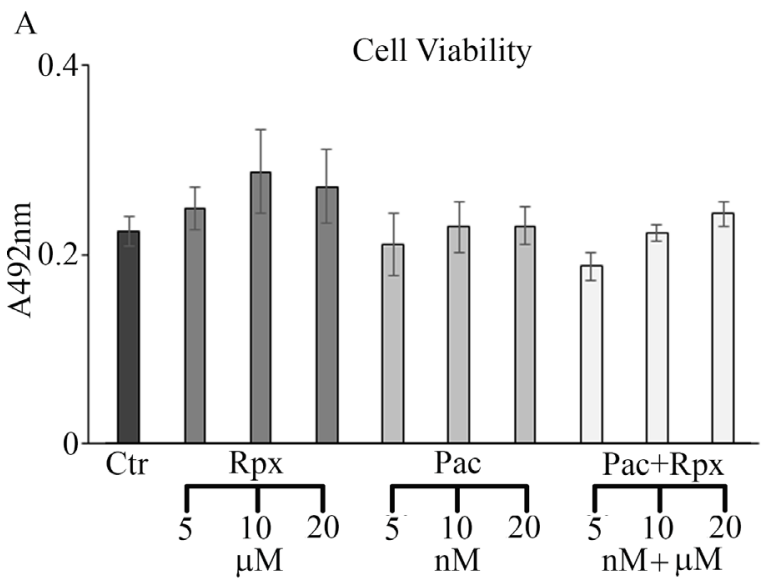

$\mathrm{B}$

Acetylated $\alpha$ tubulin
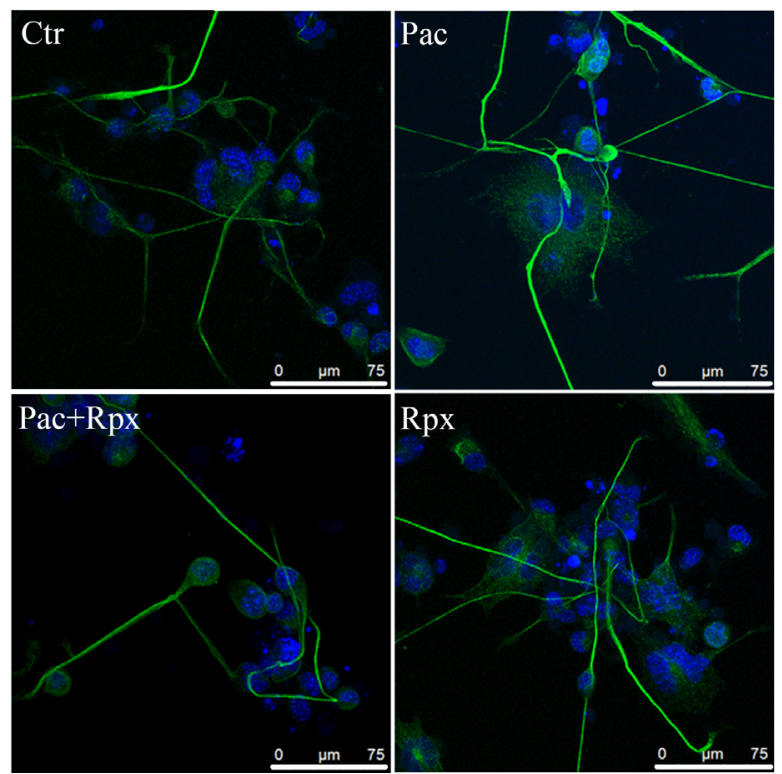

incubated with paclitaxel for $24 \mathrm{~h}$ and levels of GRO/ $\mathrm{KC}$ released into the culture medium were quantitated by ELISA assay. The obtained results showed that paclitaxel was able to induce a significant increase in $\mathrm{GRO} / \mathrm{KC}$ release (Figure 5).

The whole CXCR1/CXCR2-mediated pathway was re-assayed in the presence of GRO/KC in place of paclitaxel, obtaining the same effects of paclitaxel (Figure 5), thus indicating that all the effects of taxol in inducing neuropathic pain biomarkers are under GRO/KC control.

Finally, the effect of reparixin on $\mathrm{GRO} / \mathrm{KC}$-induced p-cortactin and p-Fak was tested; in line with the previous experimental data, reparixin markedly inhibited both the biomarkers (Figure 5F and 5G).

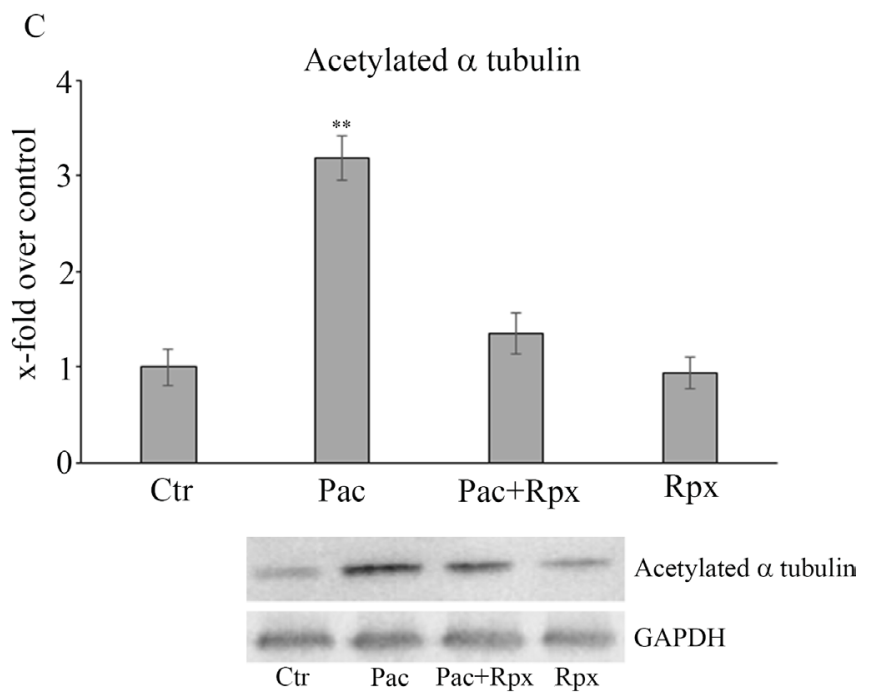

$\mathrm{D}$

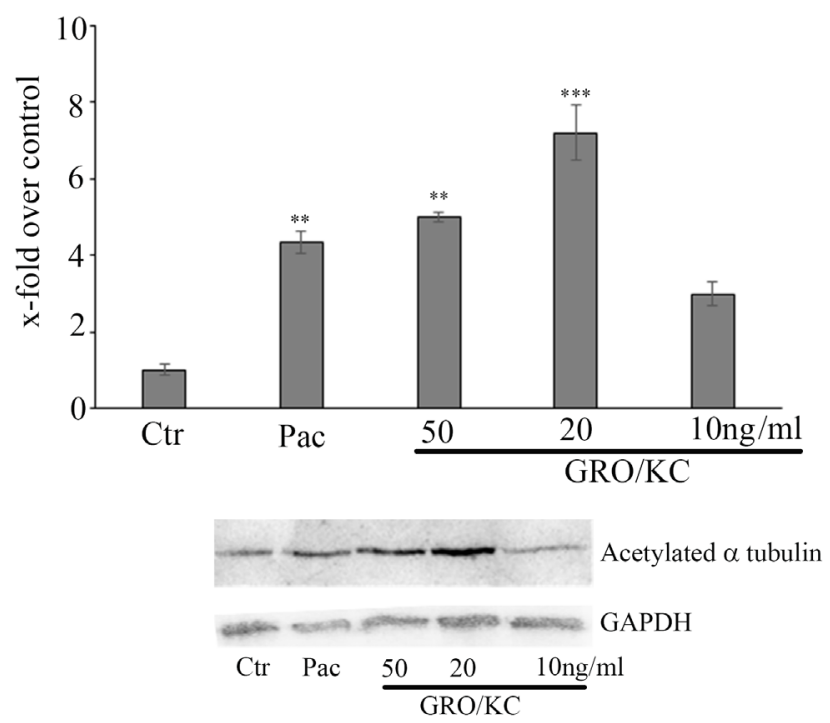

Figure 2: cell viability assay under the different treatments. (A) Control, paclitaxel and reparixin treated neurons probed for anti-acetylated $\alpha$-tubulin are shown (B) In panel (C) the western blotting and densitometric analyses for acetylated $\alpha$-tubulin are reported. In order to determine whether the observed effects may be triggered by the CXCR2 natural ligand, GRO/KC, was used. In panel, (D) acetylated $\alpha$-tubulin was re-assayed by western blotting under GRO/KC treatment at different concentrations, and compared to paclitaxel treatment. Data are mean $\pm \mathrm{SE}$ of 3 different experiments. ${ }^{*} p<0.005 ; * * * p<0.0005$. Bar $=75 \mu \mathrm{m}$. 


\section{DISCUSSION}

CIPN is a common and potentially severe adverse effect associated with MTSA therapy [31] and taxaneinduced neuropathy is by far the most extensively investigated in preclinical and clinical studies. Such a neuropathy, usually presenting as sensory neuropathy, is more frequently associated with paclitaxel than docetaxel and seems to depend on the dose per treatment cycle, the schedule of treatment, and the duration of the infusion. Despite clinical efforts to minimize paclitaxelinduced neurotoxicity, no drugs are approved as of today to prevent or treat CIPN, which often requires dose reduction or treatment interruption with a major impact on patients quality of life and clinical outcome $[4,2,5]$.

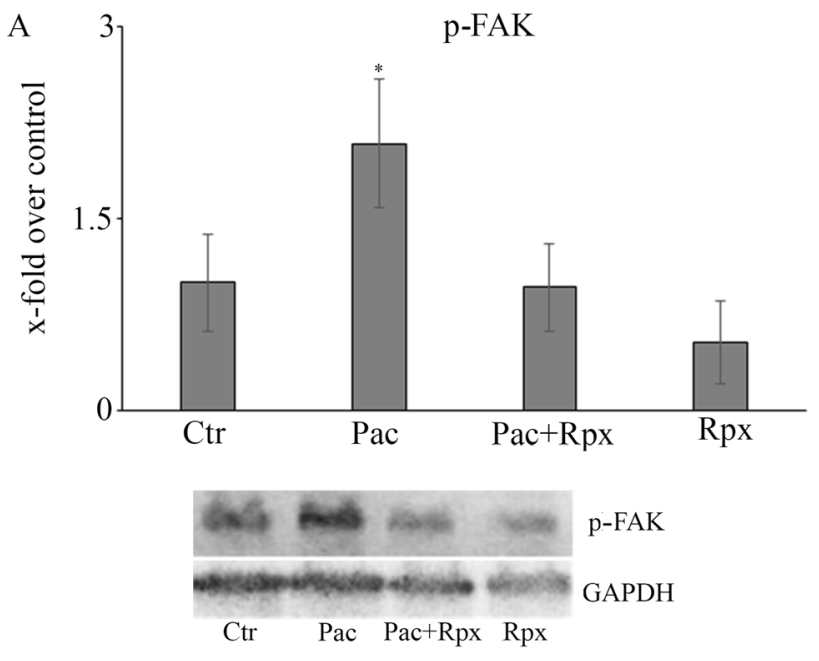

B
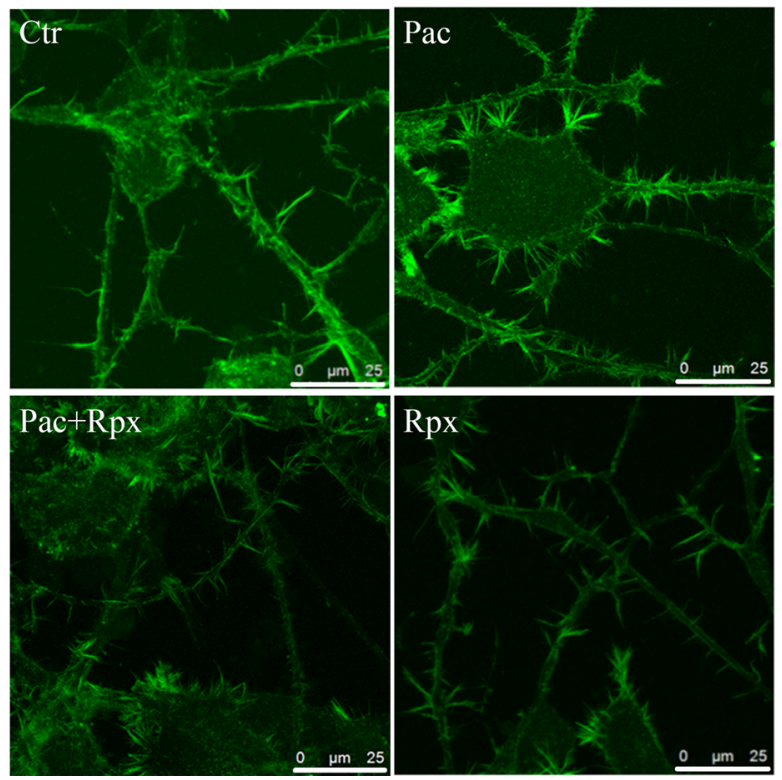

Taxanes bind the inner surface along the entire length of microtubules promoting their stabilization by suppression of microtubule shortening events [32]. In addition to their important function in cell division, microtubules play an essential role in cell morphology and intracellular transport [33]. Accordingly taxane-induced CIPN has been for a long time interpreted as a consequence of MTSA interference with normal microtubule-dependent axonal transport leading to interruption of axoplasmic flow and, as a consequence, to damage of peripheral nerves [34].

Along the last decades, great effort has been made to further investigate the underlying physiopathological mechanisms and additional evidences emerged [9, 3538] suggesting several alternative mechanisms $[6,39]$. Among those, extensive research has been dedicated to

C
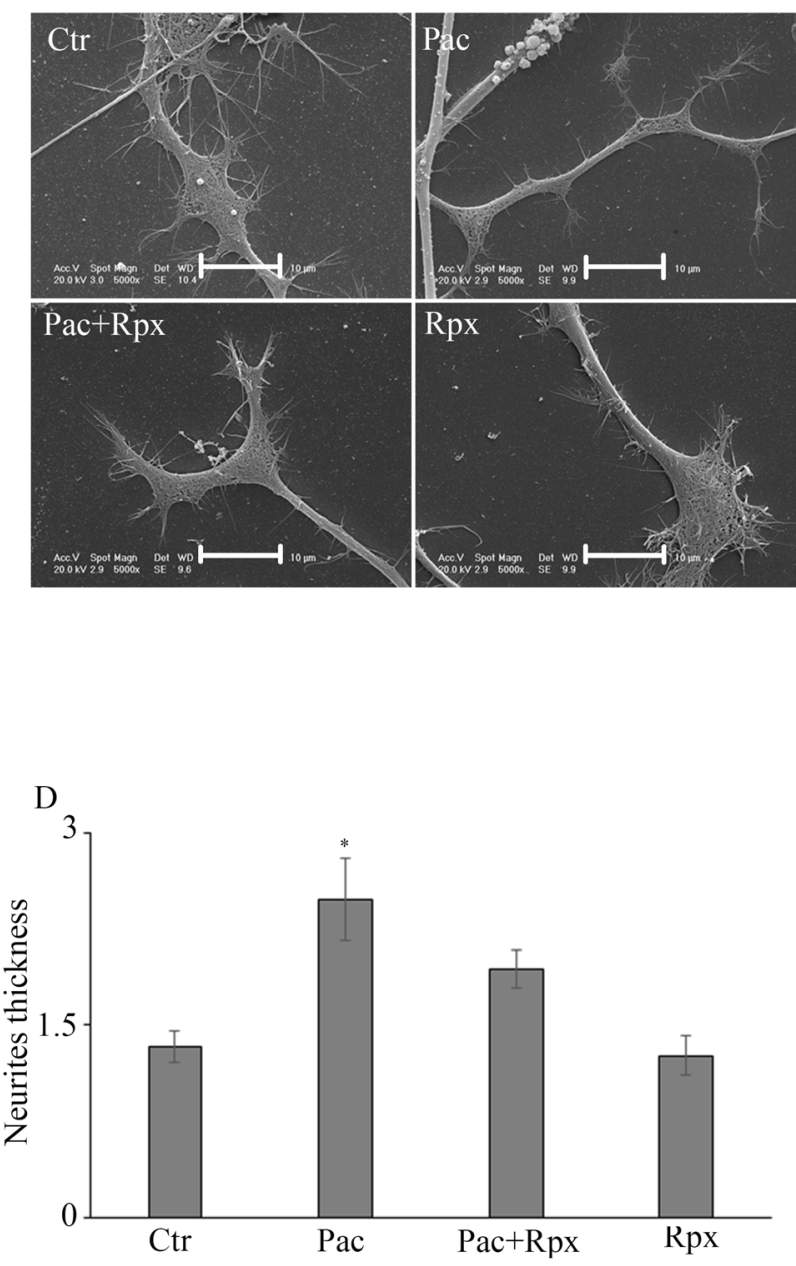

Figure 3:(A) Western blotting analysis for the active form of the protein of fokal adhesion, p-FAK. In panel (B) the localization for the cytoskeletal component actin on control and treated cells is reported. The SEM analysis were also performed and reported in panel (C). By the mean of actin localization also neurite thickness was calculated (panel D). Data are mean \pm SE of 3 different experiments. $* p<0.05 ; \mathrm{Bar}=25 \mu \mathrm{m}$. 
chemotherapy-induced inflammation as the potential common driver of CIPN. Several independent studies concur to demonstrate a chemotherapy-induced increase of peripheral pro-inflammatory and chemoactractant cytokine levels and an apparent correlation with behavioral toxicities and peripheral neuropathy $[11,40]$.

Inflammatory cytokines and chemokines ( TNF $\alpha$, IL-1 $\beta$, IL-6, CCL2, IL-8), produced and secreted by neurons and by infiltrated macrophages in response to the chemotherapy-induced injury, can cause neurotoxicity not only by triggering the inflammatory response but also by modulating spontaneous nociceptor sensitivity and activity [41-42]. The key role of pro-inflammatory mediators in the development of CIPN has found important confirmations in preclinical studies that proved the efficacy of specific IL-1 $\beta$ and $\mathrm{TNF} \alpha$ blockage in attenuating peripheral neuropathy in relevant animal models [16, 28, 43].
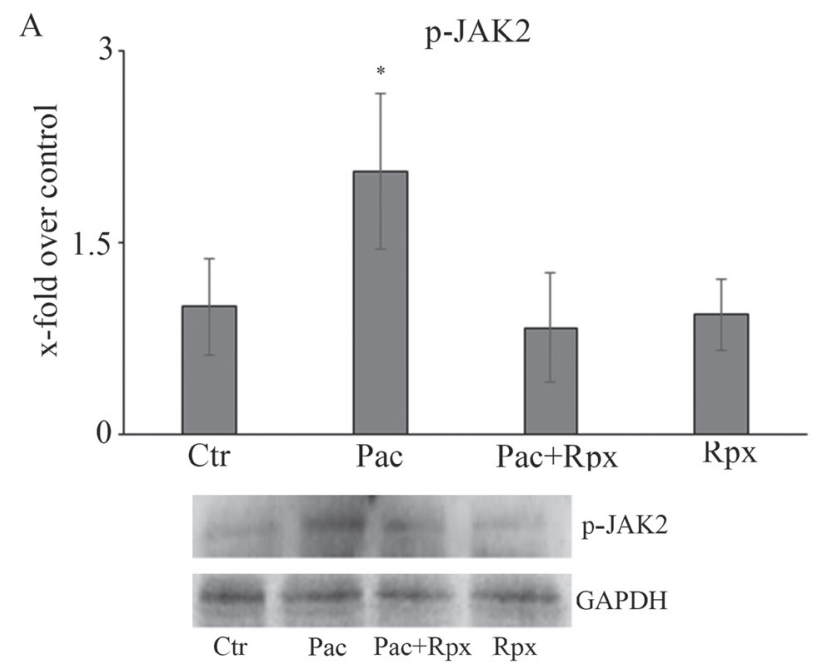

B
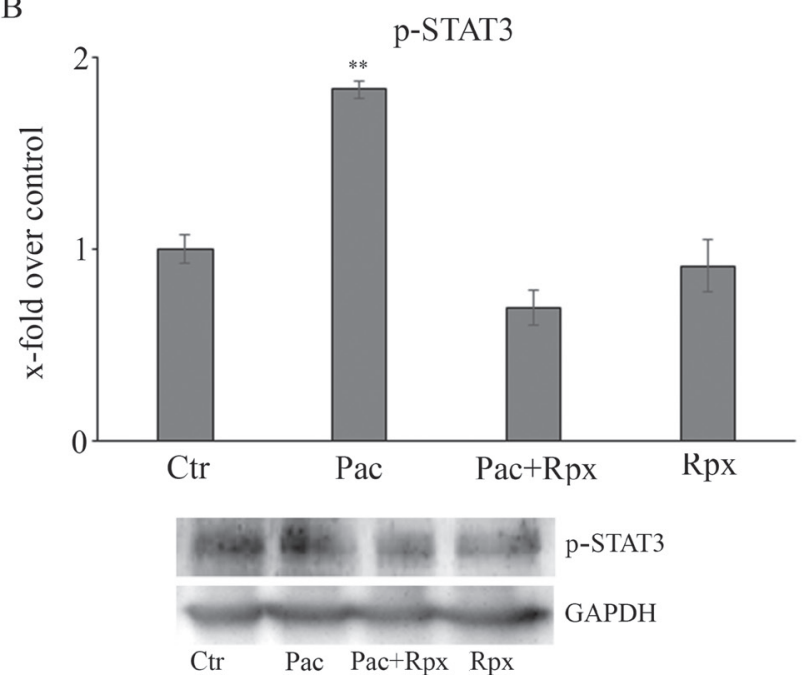

Chemokine signaling in leukocytes is mediated by the specific interaction with membrane receptors that belong to the large family of $\mathrm{G}$ protein-coupled receptors (GPCRs) [44]. Compelling evidence demonstrated that chemokine receptors are also expressed in neurons and astrocytes and significantly up-regulated during both early-phase and late-phase of chronic pain suggesting an implication of this pathway in neuroinflammation [45].

Among the chemokines family, IL-8 and its receptors CXCR1/2 have been emerging as one of the most promising target for the pharmacological management of CIPN due to its implication in sympathetic components of inflammatory hypernociception and in neuropathic nociceptive response [46-47]. Interestingly, a recent controlled clinical study showed a significant upregulation of IL8 gene expression in the skin biopsies of patients affected by CIPN [23]. Also, the results of a recently completed phase $\mathrm{Ib}$ trial in metastatic breast

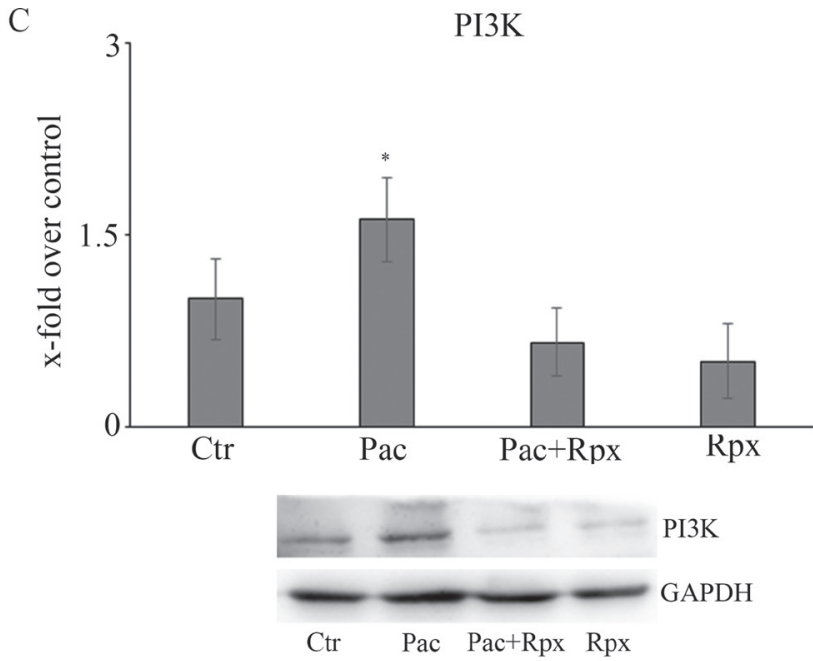

D

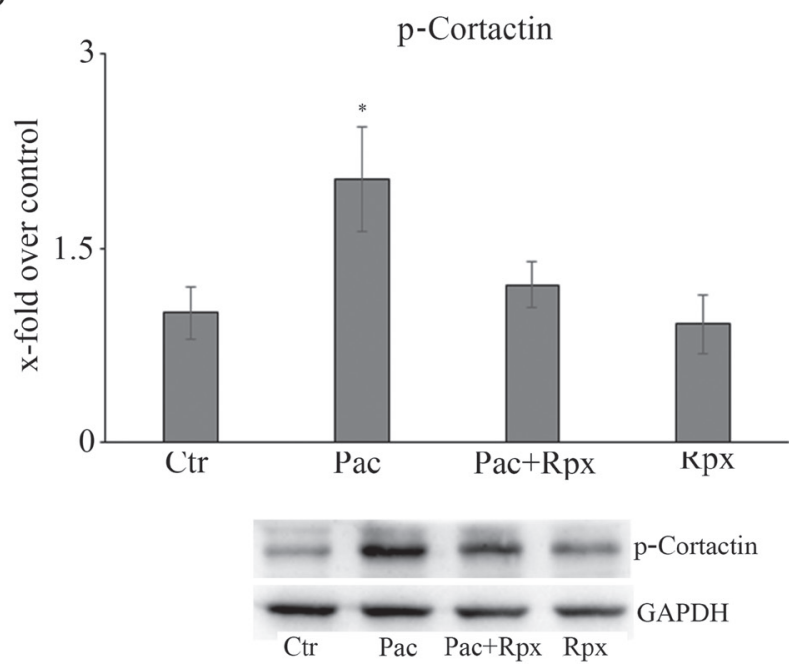

Figure 4: Western blotting analysis for the active form of the JAK2 protein, involved in the p-STAT3 signaling (A). In panel $\mathbf{B}, \mathrm{p}$-STAT3 levels, under the different conditions. In panels $(\mathbf{C}$ and $\mathbf{D})$, the pathway PI3K-p-cortactin is reported. Data are mean \pm SE of 3 different experiments. $* p<0.05 ; * p<0.005$. 


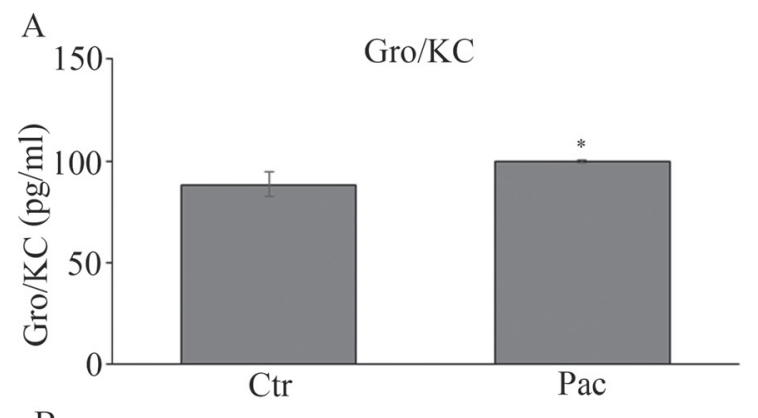

$\mathrm{E}$

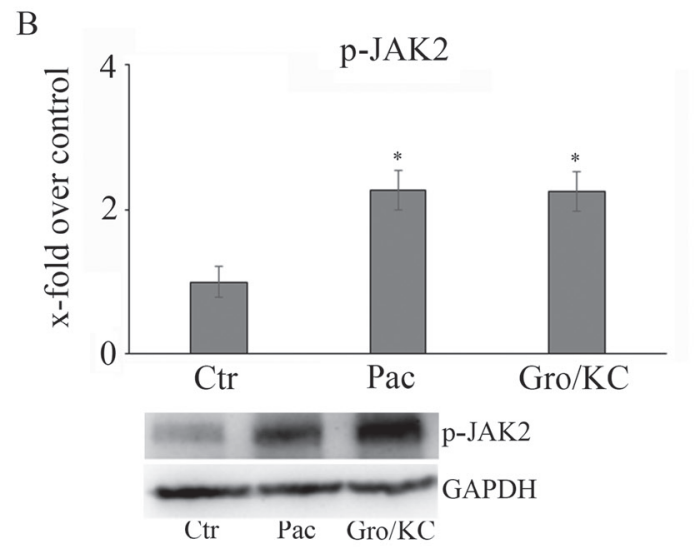

$\mathrm{C}$
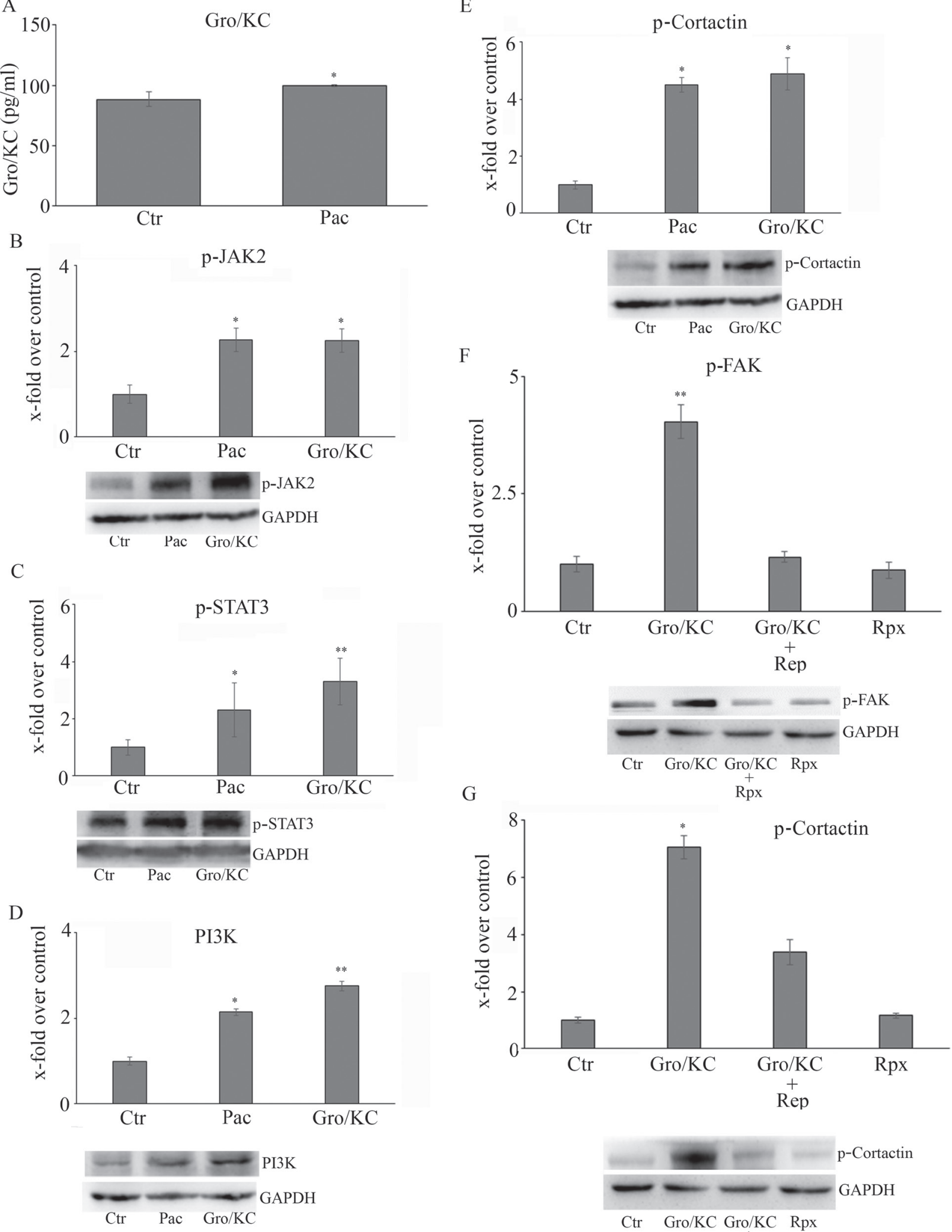

Figure 5: (A) GRO/KC 5 levels released into the culture medium, quantitated by ELISA assay The whole CXCR1/CXCR2mediated pathway re-assayed in the presence of GRO/KC in the place of paclitaxel is shown in Panels (B-E). The effects of reparixin on GRO/KC-induced p-cortactin and p-Fak is reported in Panels (F and $\mathbf{G})$. Data are mean $\pm \mathrm{SE}$ of 3 different experiments. ${ }^{*} p<0.05 ; * * p<0.005$. 
cancer, showed that combination of reparixin with weekly paclitaxel resulted in a sizeable response rate with a low incidence and severity of peripheral neuropathy, suggesting that taxane-induced neurological toxicity, but not antitumor activity, may be reduced by CXCR $1 / 2$ inhibition [27].

Starting from this observation and with the aim to dissect molecular mechanisms underlying the effects of CXCR1/CXCR2 blocking compounds in counteracting initiation and progression of paclitaxel-induced peripheral neuropathy, we evaluated direct effects of IL-8-induced signaling in DRG derived neurons cultures.

Tubulin acetylation participates the complex process regulating microtubule dynamics that is influenced by a number of different microtubule-associated proteins (MAPs), including the end binding proteins EB1 and EB3 implicated in the promotion of microtubule growth and axonal transport and in linking dynamic microtubules with the actin cytoskeleton [48-50]. In our experimental conditions, the paclitaxel-induced increase of $\alpha$-acetylated tubulin in DRG derived neurons was efficiently counteracted by the presence of reparixin. Reparixin effects were also apparent on the signal transduction pathways dissected in the study. IL-8 is significantly upregulated by paclitaxel in DRG derived neurons. Even though the observed expression increase was relatively modest, it was sufficient to trigger the activation of IL-8 signal upon paclitaxel treatment.

Under paclitaxel treatment DRG derived neurons were shown to express higher levels of p-JAK2 which in turn activates p-STAT3, known to be involved in neuropathic pain and synaptic plasticity [29-30]. Additionally, exposure to paclitaxel was shown to increase the active form of fokal adhesion kinase (p-FAK), involved in microtubule stabilization [51], and to activate the PI3K-p-cortactin pathway that ultimately leads to terminal axonal arborization and synaptic plasticity [52]. With the aim to confirm the hypothesis that paclitaxel-induced neurotoxic effects are mainly mediated by IL8, the expression of CXCR2 and the effects of $\mathrm{GRO} / \mathrm{KC}$ treatment on F11 were investigated. CXCR2 was found expressed on F11 (data not shown) and receptor binding of IL8 triggered the same pathways activated by paclitaxel. In agreement with the observed in vivo effect, CXCR2 inhibition by reparixin significantly counteracted p-STAT3, p-FAK and PI3K-p-cortactin activation induced either by paclitaxel or $\mathrm{GRO} / \mathrm{KC}$.

In summary, the majority of the effects of paclitaxel on DRG derived neurons in culture seem to be mediated by the $\mathrm{GRO} / \mathrm{KC}$-dependent pathway and blockade of $\mathrm{GRO} / \mathrm{KC}$ receptors by reparixin effectively inhibited in vitro and in vivo paclitaxel-induced neurotoxic effects.

In breast cancer models, reparixin showed the ability to reduce the CSC population in vitro and in tumor xenografts. It is remarkable how the signaling pattern activated by paclitaxel/IL8 in F11, putatively responsible for neurons sensitization, is largely the same pattern that in breast cancer tumor cells was reported to promote tumor growth and invasiveness. In a recent paper the effects of reparixin on paclitaxel-induced signaling was studied in highly purified mammospheres derived from triple negative MDA-MB231 breast cancer cells showing that its effect in breast cancer cells was mediated by inhibition of paclitaxel/GRO/KC-induced p-FAK, p-AKT, p-STAT3 and $\beta$-catenin activation [26].

FAK is a cytoplasmic tyrosine kinase identified as a key mediator of intracellular signaling by integrins involved in the regulation of different cellular functions in a variety of cells [53-54]. Consistent with reparixin pharmacological effects, p-FAK activation in breast cancer cells was previously reported to be implicated in anchorageindependent growth [55] and in breast cancer tumorigenesis and progression [56-60] whereas in sensory neurons $\beta 1$ integrin activity and FAK phosphorylation at tyrosine 397 (FAKpY397) are linked to neuronal polarization as well as neurite outgrowth and branching [61].

The avoidance of pFAK activation by CXCR $1 / 2$ inhibition in breast cancer cells results in sensitization and reduction of migrative potential of stem cells, while the inhibition of the same pathway in peripheral sensory neurons, promoted by taxane treatment via exocrine and endocrine IL-8 production, may efficiently prevent microtubule acetylation, terminal axons arborization and synaptic plasticity thus modulating the key features of chemotherapy-associated neurotoxicity.

Since the cytotoxic effect of taxanes on cancer cells is strictly associated with the ability to stabilize microtubules and to promote net microtubule polymerization, the effect of reparixin treatment on $\alpha$-tubulin association observed in sensory neurons was investigated with the aim to understand potential implication on cancer cells biology.

Biochemically, also in cancer cells paclitaxel induces $\alpha$-tubulin expression and acetylation. While tubulin acetylation has historically been viewed as a marker but not a cause of microtubule stability, recent work suggests an active role of the tubulin acetylation/ deacetylation process in the regulation of cell motility [6264]. In particular, the inhibition of tubulin deacetylation mediated by two identified tubulin deacetylases HDAC6 and SIRT2 enhances sensitivity to the anti-motility activity of paclitaxel theoretically potentiating the antitumor effect of the drug [65-67]. In this perspective, we investigated in this paper the effect of paclitaxel on $\alpha$-tubulin acetylation, the outcome of reparixin inhibition on paclitaxel-induced tubulin acetylation in MDAMB231-derived breast cancer stem tumorspheres. The evidence that reparixin did not inhibit paclitaxel-induced tubulin acetylation in MDA-MB231 is coherent with the reported synergic effect of reparixin and paclitaxel on breast cancer cell survival, motility and invasiveness. The apparently divergent effect of reparixin combination on neural and cancer cells functionality is coherent with the 
specific pathways activated by $\mathrm{CXCR} 1 / 2$ receptors in the two different cellular contexts.

Overall the results described in this paper for the first time provide evidences that IL- 8 and its receptors CXCR1/2 play a key role in the induction and progression of peripheral neuropathy and reinforce the hypothesis that CXCR1/2 inhibitors combined with standard taxane therapy might potentiate the taxane anti-tumor activity and reduce the chemotherapy-induced neurotoxicity. Since JAK2, STAT3 and PI3K pathways are also involved in several other activities such as apoptosis and senescence, that are two phenomena that could be induced by anticancer drugs, future investigations will be performed in order to evaluate if treatment with reparixin may have any effect on these phenomena as already described by other Authors in different cancer cells [68-70].

\section{MATERIALS AND METHODS}

\section{In vivo model}

\section{Animals}

The behavioral experiments were performed on male Wistar rats (200-250 g, Harlan Italy) housed in the animal care facility of the Department of Pharmacy of the University of Naples Federico II, Italy. Animals were housed in a room with controlled temperature $\left(22 \pm 1{ }^{\circ} \mathrm{C}\right)$, humidity $(60 \pm 10 \%)$ and light ( $12 \mathrm{~h}$ per day); food and water were available ad libitum. All behavioral tests were performed between 9:00 AM and 5:00 PM, and the animals were used only once. Animal care and manipulations were conducted in conformity with International and National law and policies (EU Directive 2010/63/EU for animal experiments, ARRIVE guidelines and the Basel declaration including the $3 \mathrm{R}$ concept). The procedure reported here were approved by the Institutional Committee on the Ethics of Animal Experiments (CVS) of the University of Naples Federico II and by Ministero della Salute under protocol n. 2014-00884607. Ten animals per group were used.

\section{Drug treatment}

Reparixin L-lysine salt was administered by continuous infusion at the effective dose of $8 \mathrm{mg} / \mathrm{hr} /$ $\mathrm{kg}$ [71] using micro-osmotic pumps (ALZET Model 2ML2 Charles River). Alzet model 2ML2 pump has an approximate $2 \mathrm{ml}$ reservoir that delivers a preloaded drug or vehicle solutions continuously for 14 days at a rate of $5 \mu \mathrm{l} / \mathrm{h}$. Pumps were filled with reparixin L-lysine salt dissolved in sterile saline at a concentration of $375 \mathrm{mg} / \mathrm{ml}$ according to the instruction of the supplier. Briefly, pumps were filled with $2 \mathrm{ml}$ of reparixin solution or vehicle (saline) using sterile syringe. Finally, pumps were kept in water bath overnight in stove at $37^{\circ} \mathrm{C}$.

\section{Surgical implantation of osmotic pumps}

Osmotic pumps were implanted under intraperitoneal (i.p.) anesthesia (100 mg/kg ketamine and $10 \mathrm{mg} / \mathrm{kg}$ xylazine). The osmotic pump was inserted through a surgical incision made on the back. Briefly, a small incision was made in the skin between the scapulae and a pocket was formed by spreading apart the subcutaneous connective tissues. The pump was inserted into the pocket with the flow moderator pointing away from the incision. Finally the incision was sutured and closed with sutures. Pumps were implanted 3 days before paclitaxel injection (day -3). The cessation of drug delivery was expected at day +11 , as represented in the below scheme, since the duration of administration of 2ML2 mini pumps is 2 weeks.

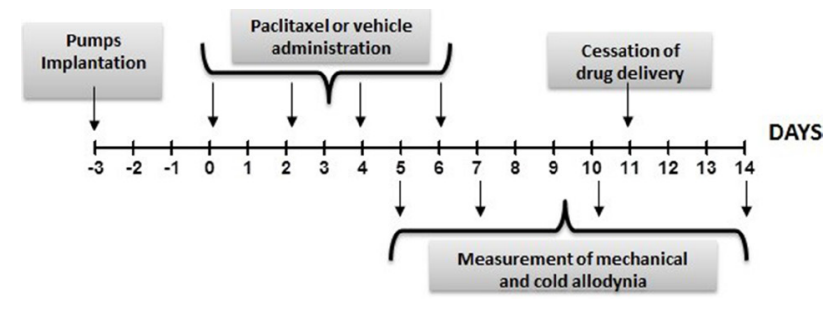

\section{Induction of neuropathy by paclitaxel}

Rats received four once daily i.p. injections of paclitaxel ( $2 \mathrm{mg} / \mathrm{kg} /$ day; cumulative dose of $8 \mathrm{mg} / \mathrm{kg}$; Tocris, Italy) or vehicle (15\% PEG400, 5\% Tween 80 and saline, $1 \mathrm{ml} / \mathrm{kg} /$ day), administered on alternate days (day 0, 2, 4, and 6) as described [9]. Behavioral testing was performed prior to paclitaxel/vehicle administration (day -1) in order to determine the basal values of the mechanical and cold nociceptive thresholds, and again on day 5-7-10-14 following paclitaxel/vehicle injection. as shown in the scheme above.

\section{Mechanical allodynia}

To assess for changes in sensation or in the development of mechanical allodynia, sensitivity to tactile stimulation was measured using the Dynamic Plantar Aesthesiometer (DPA, Ugo Basile, Italy), which is an automated version of the von Frey hair assessment [72]. Individual animals were placed in Plexiglas boxes $(30 \times 30 \times 25 \mathrm{~cm})$ with a mesh metal floor covered by a plastic dome that enabled the animal to walk freely, but not to jump. When a trial is initiated, the device raises the filament to touch the foot and progressively increases force until the animal withdraws its foot, or until it reaches a maximum of $50 \mathrm{~g}$ of force (cut-off). The DPA automatically records the force at which the foot is withdrawn. This test does not require any special pretraining, just an acclimation period to the environment and testing procedure. Each paw was tested twice per 
session and the test was performed on both paws on day before (day -1) paclitaxel or vehicle first administration and then on 5th, 7th, 10th and 14th days after paclitaxel or vehicle first administration. No consistent left and right differences were observed. The means of the paws withdrawal (expressed in gram) were calculated from an average of four separate measures.

\section{Cold allodynia}

Cold sensitivity was measured as the number of foot withdrawal responses after application of acetone to the dorsal surface of the paw [9; 73]. Individual animals were placed in Plexiglas boxes $(30 \times 30 \times 25 \mathrm{~cm})$. A drop of acetone $(25 \mu \mathrm{L})$ was applied to the dorsal surface of paws with a syringe connected to a thin polyethylene tube while the rats was standing on a metal mesh. A brisk foot withdrawal response, after the spread of acetone over the dorsal surface of the paw, was considered as a sign of cold allodynia. The procedure was repeated three times at 5 minutes intervals on both paws. The mean of the paw withdrawal (expressed in number) was determined from an average of six separate measures. Cold responses were measured before paclitaxel or vehicle first administration (day -1) and then on 5th, 7th, 10th and 14th days after. No consistent left and right differences were observed.

\section{In vitro models}

\section{Cell culture and treatments}

The F11 hybridoma cells (ECACC 08062601), chosen as model of dorsal root ganglion (DRG) neurons [74-75] were cultivated in DMEM (Euroclone, MI, Italy) medium supplemented with 10\% FBS (Sigma-Aldrich St. Louis, CO, USA), 1\% penicillin/streptomycin (Euroclone) and $1 \%$ glutamine (Euroclone) at $37^{\circ} \mathrm{C}$, in a humidified 95\% air-5\% $\mathrm{CO}_{2}$ atmosphere. For all the experiments cells were used at 18 th passage. For immunofluorescence analysis cells were seeded on coverslips at $1 \times 10^{4}$ cells $/ \mathrm{cm}^{2}$ for $24 \mathrm{~h}$. After, cells were differentiated with mouse NGF (mNGF) (from Dompé farmaceutici S.p.A., L'Aquila, Italy). mNGF was dissolved in DMEM with 1\% penicillin/streptomycin and 1\% glutamine (FBS free) at the final concentration $50 \mathrm{ng} / \mathrm{ml}$. Medium was replaced every 3 days until complete differentiation, that happened after 7 days.

Following neuronal differentiation, neurons were treated for 24 hours with reparixin (Dompé farmaceutici S.p.A.; $10 \mu \mathrm{M}$ final concentration), paclitaxel (SigmaAldrich; $10 \mathrm{nM}$ final concentration) and the combination of the two molecules.

Reparixin stock solution $(53 \mathrm{mM})$ was prepared freshly dissolving 7,5 $\mathrm{mg}$ of reparixin in $0,5 \mathrm{ml}$ of Phosphate Buffer in addition to $5 \mu \mathrm{NaOH}$. Paclitaxel stocks solution $(10 \mathrm{mM})$ was prepared dissolving the powder in DMSO and aliquots were stored at $-20^{\circ} \mathrm{C}$.
In some experiments, GRO/KC (PeproTech NJ, USA) was used (at 50, 20, $10 \mathrm{ng} / \mathrm{ml}$ ) in comparison to paclitaxel. GRO/KC stock solution $(0.1 \mathrm{mg} / \mathrm{ml})$ was prepared dissolving the powder in $0.1 \%$ BSA in PBS; aliquots were stored at $-20^{\circ} \mathrm{C}$.

\section{MTS assay}

Cell viability was determined at $24 \mathrm{~h}$ using Cell Titer One Solution Cell Proliferation Assay (Promega Corporation Madison, WI, USA) a colorimetric method based on 3-(4,5-dimethylthiazol-2-yl)-5-(3carboxymethoxyphenil)-2-(4-sulfophenyl)-2H-tetrazolium (MTS). The quantity of formazan formed, as a function of viability, was measured at $492 \mathrm{~nm}$ using an ELISA plate reader, Infinite F200 (Tecan, Männedorf, Swiss). The assay was performed in quintuplicate. The results were expressed as absorbance at $492 \mathrm{~nm}$.

\section{Immunofluorescence}

Cells were fixed in 4\% paraformaldehyde in PBS for $20 \mathrm{~min}$ at room temperature (RT) and permeabilized in methanol for $5 \mathrm{~min}$ at $-20^{\circ} \mathrm{C}$. Cells were then blocked with PBS containing 4\% BSA for $30 \mathrm{~min}$ and incubated with the following primary antibodies diluted in the blocking solution overnight at $4{ }^{\circ} \mathrm{C}$ : rabbit $\beta$-tubulin (Abcam, Cambridge, UK ) 1:200; mouse $\alpha$-tubulin (Abcam) 1:1000; mouse acetylated $\alpha$-tubulin (Abcam) 1:500. Cells were then rinsed in PBS several times before incubation with secondary antibodies, goat anti rabbit conjugated with Alexafluor 633 (1:2000), goat anti mouse conjugated with Alexafluor 488 (1:2000), (Life Technologies, CA, USA) for $30 \mathrm{~min}$ at RT. After extensive washing, coverslips were mounted with Vectashield mounting medium with DAPI (Vector Laboratories Burlingame, CA, USA) and then observed at a Leica TCS SP5 confocal microscope (Mannheim, Germany).

\section{Phalloidin staining}

Cells were fixed in 4\% paraformaldehyde in PBS for $10 \mathrm{~min}$ at RT and permeabilized in TritonX100 0.1\% for $5 \mathrm{~min}$ at $-20^{\circ} \mathrm{C}$. Cells were incubated overnight at $4^{\circ} \mathrm{C}$ with Phalloidin-FITCH (5mg/ml; Sigma-Aldrich) diluted in PBS. After extensive washing with PBS, coverslips were mounted with Vectashield mounting medium with DAPI (Vector Laboratories Burlingame, CA, USA) and then observed at confocal laser microscope.

\section{Neurite thickness}

Neurite thickness was analyzed by ImageJ software by converting pixels related to single neurite in $\mu \mathrm{m}$. For each neurite at least 3 different measurements at different levels were averaged. For each treatment at least 5 fields were counted. 


\section{Western blotting}

Control and treated cells were collected and lysated in ice-cold RIPA buffer (phosphate buffer saline $\mathrm{pH} 7.4$ containing $0.5 \%$ sodium deoxycolate, $1 \%$ Nonidet P- 40 , $0.1 \%$ SDS, $5 \mathrm{mM}$ EDTA, $1 \%$ protease and phosphatase inhibitor cocktails, Sigma). Protein lysates (30 $\mu \mathrm{g} ; 15$ $\mu \mathrm{g}$ only for acetylated $\alpha$-tubulin) were separated on 7-10\% SDS-polyacrilamide gel and electroblotted onto polyvinyldifluoride membrane (PVDF; Sigma). Nonspecific binding sites were blocked by $5 \%$ non-fat dry milk (Bio-Rad Laboratories, Hercules, CA) in Tris buffered saline (TBS: 20mMTris- $\mathrm{HCl}, \mathrm{pH} 7,4$, containing $150 \mathrm{mM}$ $\mathrm{NaCl}$ ) for $30 \mathrm{~min}$ at RT. Membranes were then incubated overnight at $4{ }^{\circ} \mathrm{C}$ with the following primary antibodies, diluted with TBS containing $0,1 \%$ Tween 20 (TBS-T) and $5 \%$ non-fat dry milk: mouse acetylated $\alpha$-tubulin 1:1000 (Abcam), rabbit p-FAK 1:500 (Santa Cruz), rabbit p-JAK2 1:500 (Santa Cruz), rabbit PI3K 1:500 (Abcam), pCortactin (1:1000) (Abcam), rabbit GAPDH 1:5000 (Santa Cruz), goat pSTAT3 1:200 (Santa Cruz). As secondary antibodies, peroxidase conjugated anti-rabbit or anti mouse IgG (1:1000; Vector Laboratories, Burlingame, CA) and antigoat (1:10000 Santa Cruz) were used. Immunoreactive bands were visualized by ECL (Pierce), according to the manufacturer's instructions. The relative densities of the immunoreactive bands were determinated and normalizated with respect to GAPDH, using ImageJ software. Values were given as relative units (RU).

\section{Scanning electron microscopy analysis}

For Scanning Electron Microscopy (SEM) observations, cells were cultured at a density of 10.000 cells $/ \mathrm{cm}^{2}$ on a round cover slip in a 4 well plate and treated with paclitaxel, reparixin or reparixin in combination with paclitaxel for $24 \mathrm{~h}$. The morphology of the F11 cells was observed using scanning electron microscope (SEM Philips XL-30 CP). The cells were fixed with $3 \%$ glutaraldehyde in PBS at RT for $20 \mathrm{~min}$ and then washed three times in PBS. Subsequently, the cells were dehydrated in graded series of cold ethanol $(30,50,70$, 85, 90, 95 and 100\%; 5 min, two times each). Dehydrated samples were dried further in a critical point dryer and coated with gold $(10 \mathrm{~nm})$ before analysis.

\section{Quantitation of GRO/KC}

The quantification of $\mathrm{GRO} / \mathrm{KC}$ released in the medium was performed using ELISA (enzyme-linked immunosorbent assay) kit (Thermo Fisher Scientific Waltham, MA, USA) using a microplate reader Infinite F200 (Tecan). Briefly, a target-specific antibody had been pre-coated in the wells of the supplied microplate, samples and standards were then added into these wells and bind to the immobilized (capture) antibody. The sandwich was formed by the addition of the second (detector) antibody, binding to the target on a different epitope from the capture antibody. A conjugated enzyme had been incorporated into the assay. After incubation periods and wash steps to remove unbound antibody from the plate, a substrate solution was added reacting with the enzyme-antibodytarget complex to produce measurable signal, measured at $450 \mathrm{~nm}$ using an ELISA plate reader. The intensity of this signal was proportional to the concentration of target present in the sample and the results were expressed in $\mathrm{pg} / \mathrm{ml}$. All ELISA assays were performed in quintuplicate.

\section{Statistics}

For the in vivo results, all data were presented as the mean \pm SE. Analysis of data was conducted using GraphPad Prism (GraphPad Software Inc., San Diego, CA). The significance of differences between groups was determined by two-way analysis of variance (ANOVA) followed by Bonferroni post hoc tests for multiple comparisons. The level of significance was set at $P<0.05$.

For the in vitro results, data were expressed as mean \pm SE. Statistical analysis was performed by the analysis of variance (ANOVA) followed by Scheffe's post hoc test analysis. The level of significance was set at $P<0.05$.

\section{ACKNOWLEDGMENTS AND FUNDING}

This work was supported by the RIA funds (Proff Cimini, Benedetti). The Authors thank to the Human Health Foundation for the support. Many of the experiments have been performed in the Research Center for Molecular Diagnostics and Advanced Therapies granted by the Abruzzo Earthquacke Relief Fund (AERF).

\section{CONFLICTS OF INTEREST}

Laura Brandoli, Pier Adelchi Ruffini and Marcello Allegretti are employes of Dompè Farmaceutici Spa, Italy. The Company has interests in the development ofCXCR1/CXCR2 allosteric modulators for the treatment of oncologic-related diseases.

\section{REFERENCES}

1. Cavaletti G, Marmiroli P. Chemotherapy-induced peripheral neurotoxicity. Nat Rev Neurol. 2010; 6:657-666.

2. Miltenburg NC, Boogerd W. Chemotherapy-induced neuropathy: A comprehensive survey. Cancer Treat Rev. 2014; 40:872-882.

3. Saretny M, Currie GL, Sena ES, Ramnarine S, Grant R, MacLeod MR, Colvin LA, Fallon M. Incidence, prevalence, and predictors of chemotherapy-induced peripheral neuropathy: a systematic review and meta-analysis. Pain. 2014; 155:2461-2470. 
4. Markman M. Chemotherapy-associated neurotoxicity: an important side effect-impacting on quality, rather than quantity, of life. J Cancer Res Clin Oncol. 1996; 122:511-512.

5. Smith EM, Pang H. Therapy for chemotherapy-induced peripheral neuropathy —in reply. JAMA. 2013; 310:538.

6. Boyette-Davis J, Xin W, Zhang H, Dougherty PM. Intraepidermal nerve fiber loss corresponds to the development of taxol-induced hyperalgesia and can be prevented by treatment with minocycline. Pain. 2011; 152:308-13.

7. Burakgazi AZ, Messersmith W, Vaidya D, Hauer P, Hoke A, Polydefkis M. Longitudinal assessment of oxaliplatininduced neuropathy. Neurology. 2011; 77:980-986.

8. Topp KS, Tanner KD, Levine JD. Damage to the cytoskeleton of large diameter sensory neurons and myelinated axons in vincristine-induced painful peripheral neuropathy in the rat. J Comp Neurol. 2000; 424:563-576.

9. Polomano RC, Mannes AJ, Clark US, Bennett GJ. A painful peripheral neuropathy in the rat produced by the chemotherapeutic drug, paclitaxel. Pain. 2001; 94:293-304.

10. Zhao Y, Mu X, Du G. Microtubule-stabilizing agents: New drug discovery and cancer therapy. Pharmacol Ther. 2016; 162:134-143.

11. Wang XM, Lehky TJ, Brell JM, Dorsey SG. Discovering cytokines as targets for chemotherapy-induced painful peripheral neuropathy. Cytokine. 2012; 59:3-9.

12. Jaggi AS, Singh N. Mechanisms in cancer-chemotherapeutic drugs-induced peripheral neuropathy. Toxicology. 2012; 291:1-9.

13. Zaks-Zilberman M, Zaks TZ, Vogel SN. Induction of proinflammatory and chemokine genes by lipopolysaccharide and paclitaxel (Taxol) in murine and human breast cancer cell lines. Cytokine. 2001; 15:156-165.

14. Basu S, Sodhi A. Increased release of interleukin-1 and tumour necrosis factor by interleukin-2-induced lymphokine-activated killer cells in the presence of cisplatin and FK-565. Immunol Cell Biol. 1992; 70:15-24.

15. Weintraub M, Adde MA, Venzon DJ, Shad AT, Horak ID, Neely JE, Seibel NL, Gootenberg J, Arndt C, Nieder ML, Magrath IT. Severe atypical neuropathy associated with administration of hematopoietic colony-stimulating factors and vincristine. J Clin Oncol. 1996;14:935-940.

16. Ledeboer A, Jekich BM, Sloane EM, Mahoney JH, Langer SJ, Milligan ED, Martin D, Maier SF, Johnson KW, Leinwand LA, Chavez RA, Watkins LR. Intrathecal interleukin-10 gene therapy attenuates paclitaxel-induced mechanical allodynia and proinflammatory cytokine expression in dorsal root ganglia in rats. Brain Behav Immun. 2007; 21:686-698.

17. Woolf CJ, Allchorne A, Safieh-Garabedian B, Poole S. Cytokines, nerve growth factor and inflammatory hyperalgesia: the contribution of tumor necrosis factor alpha. Br J Pharmacol. 1997; 121:417-424.

18. Binshtok AM, Wang H, Zimmermann K, Amaya F, Vardeh D, Shi L, Brenner GJ, Ji RR, Bean BP, Woolf CJ,
Samad TA. Nociceptors are Interleukin-1 beta Sensors. J Neurosci. 2008; 28:14062-14073.

19. Ozaktay AC, Cavanaugh JM, Asik I, DeLeo JA, Weinstein JN. Dorsal root sensitivity to interleukin-1 beta, interleukin-6 and tumor necrosis factor in rats. Eur Spine J. 2002; $11: 467-475$.

20. Ubogu EE, Cossoy MB, Ransohoff RM. The expression and function of chemokines involved in CNS inflammation. Trends Pharmacol Sci. 2006; 27:48-55.

21. Zhang JM, An J. Cytokines, inflammation, and pain. Int Anesthesiol Clinics. 2007; 45:27-37.

22. Verri Jr WA, Cunha TM, Parada CA, Poole S, Cunha FQ, Ferreira SH. Hypernociceptive role of cytokines and chemokines: targets for analgesic drug development? Pharmacol Ther. 2006; 112:116-138.

23. Uçeyler N, Kafke W, Riediger N, He L, Necula G, Toyka KV, Sommer C. Elevated proinflammatory cytokine expression in affected skin in small fiber neuropathy. Neurology. 2010; 74:1806-1813.

24. Bertini R, Allegretti M, Bizzarri C, Moriconi A, Locati M, Zampella G, Cervellera MN, Di Cioccio V, Cesta MC, Galliera E, Martinez FO, Di Bitondo R, Troiani G, et al. Noncompetitive allosteric inhibitors of the inflammatory chemokine receptors CXCR1 and CXCR2: prevention of reperfusion injury. Proc Natl Acad Sci USA. 2004; 101:11791-11796.

25. Ginestier C, Liu S, Diebel ME, Korkaya H, Luo M, Brown M, Wicinski J, Cabaud O, Charafe-Jauffret E, Birnbaum D, Guan JL, Dontu G, Wicha MS. CXCR1 blockade selectively targets human breast cancer stem cells in vitro and in xenografts. J Clin Invest. 2010; 120:485-97.

26. Brandolini L, Cristiano L, Fidoamore A, De Pizzol M, Di Giacomo E, Florio TM, Confalone G, Galante A, Cinque B, Benedetti E, Ruffini PA, Cifone MG, Giordano A, et al. Targeting CXCR1 on breast cancer stem cells: signaling pathways and clinical application modelling. Oncotarget. 2015; 6:43375-94. doi: 10.18632/oncotarget.6234.

27. Schott AF, Wicha MS, Perez R, Kato G, Avery T, Cristofanilli M, Reuben JM, Alpaugh RK, McCanna S, Ruffini PA, Goldstein LJ. A phase Ib study of the CXCR1/2 inhibitor reparixin in combination with weekly paclitaxel in metastatic HER2 negative breast cancer - Final analysis. AACR-NCI-EORTC International Conference on Molecular Targets and Cancer Therapeutics, 2015 abstract C22 Mol Cancer Ther. 2015; 14.

28. Canta A, Chiorazzi A, Cavaletti G. Tubulin: a target for antineoplastic drugs into the cancer cells but also in the peripheral nervous system. Curr Med Chem. 2009; 16:1315-1324.

29. Xue ZJ, Shen L, Wang ZY, Hui SY, Huang YG, Ma C. STAT3 inhibitor WP1066 as a novel therapeutic agent for bCCI neuropathic pain rats. Brain Res. 2014; 1583:79-88.

30. Nicolas CS, Amici M, Bortolotto ZA, Doherty A, Csaba Z, Fafouri A, Dournaud P, Gressens P, Collingridge GL, 
Peineau S. The role of JAK-STAT signaling within the CNS. JAKSTAT. 2013; 2:e22925.

31. Benbow SJ, Cook BM, Reifert J, Wozniak KM, Slusher BS, Littlefield BA, Wilson L, Jordan MA, Feinstein SC. Effects of Paclitaxel and Eribulin in Mouse Sciatic Nerve: A Microtubule-Based Rationale for the Differential Induction of Chemotherapy-Induced Peripheral Neuropathy. Neurotox Res. 2016; 29:299-313.

32. Derry WB, Wilson L, Jordan MA. Substoichiometric binding of taxol suppresses microtubule dynamics. Biochemistry. 1995; 34:2203-2211.

33. Carlson K, Ocean AJ. Peripheral neuropathy with microtubule-targeting agents: occurrence and management approach. Clin Breast Cancer. 2011; 11:73-81.

34. Morfini GA, Burns M, Binder LI, Kanaan NM, LaPointe N, Bosco DA, Brown RH Jr, Brown H, Tiwari A, Hayward L, Edgar J, Nave KA, Garberrn J, et al. Axonal transport defects in neurodegenerative diseases. J Neurosci. 2009; 29:12776-12786.

35. Horie H, Takenaka T, Ito S, Kim SU. Taxol counteracts colchicine blockade of axonal transport in neurites of cultured dorsal root ganglion cells. Brain Res. 1987; 420:144-146.

36. Archer DR, Dahlin LB, McLean WG. Changes in slow axonal transport of tubulin induced by local application of colchicine to rabbit vagus nerve. Acta Physiol Scand. 1994; 150:57-65.

37. Dahlstrom A. Effect of colchicine on transport of amine storage granules in sympathetic nerve of rat. Eur $\mathrm{J}$ Pharmacol. 1968; 5:111-113.

38. Younger DS, Mayer SA, Weimer LH, Alderson LM, Seplowitz AH, Lovelace RE. Colchicine induced myopathy and neuropathy. Neurology. 1991; 41:943-944.

39. Vichaya EG, Chiu GS, Krukowski K, Lacourt TE, Kavelaars A, Dantzer R, Heijnen CJ, Walker AK. Mechanisms of chemotherapy-induced behavioral toxicities. Front Neurosci. 2015; 9:131.

40. Vendrell I, Macedo D, Alho I, Dionísio MR, Costa L. Treatment of Cancer Pain by Targeting Cytokines. Mediators Inflamm. 2015; 984570.

41. Mangiacavalli S, Corso A, De Amici M, Varettoni M, Alfonsi E, Lozza A, Lazzarino M. Emergent T-helper2 profile with high interleukin-6 levels correlates with the appearance of bortezomib-induced neuropathic pain. Br J Haematol. 2010; 149:916-918.

42. Schafers M, Sorkin L. Effect of cytokines on neuronal excitability. Neurosci Lett. 2008; 437:188-193.

43. Alé A, Bruna J, Morell M, van de Velde H, Monbaliu J, Navarro X, Udina E. Treatment with anti-TNF alpha protects against the neuropathy induced by the proteasome inhibitor bortezomib in a mouse model. Exp Neurol. 2014; 253:165-173.
44. Griffith JW, Sokol CL, Luster AD. Chemokines and chemokine receptors: positioning cells for host defense and immunity. Annual Review of Immunology. 2014; 32:659-702.

45. White FA, Wilson NM. Chemokines as pain mediators and modulators. Curr Opin Anaesthesiol. 2008; 21:580-585.

46. Cunha TM, Barsante MM, Guerrero AT, Verri WA Jr, Ferreira SH, Coelho FM, Bertini R, Di Giacinto C, Allegretti M, Cunha FQ, Teixeira MM. Treatment with DF 2162, a noncompetitive allosteric inhibitor of CXCR $1 / 2$, diminishes neutrophil influx and inflammatory hypernociception in mice. Br J Pharmacol. 2008; 154:460-470.

47. Kim SJ, Park SM, Cho YW, Jung YJ, Lee DG, Jang SH, Park HW, Hwang SJ, Ahn SH. Changes in expression of mRNA for interleukin- 8 and effects of interleukin-8 receptor inhibitor in the spinal dorsal horn in a rat model of lumbar disc herniation. Spine (Phila Pa 1976). 2011; 36:2139-2146.

48. Geraldo S, Khanzada UK, Parsons M, Chilton JK, GordonWeeks PR. Targeting of the F-actin-binding protein drebrin by the microtubule plus-tip protein EB3 is required for neuritogenesis. Nat Cell Biol. 2008; 10:1181-1189.

49. Gu C, Zhou W, Puthenveedu MA, Xu M, Jan YN, Jan LY. The microtubule plus-end tracking protein EB1 is required for $\mathrm{Kv} 1$ voltage-gated $\mathrm{K}+$ channel axonal targeting. Neuron. 2006; 52:803-816.

50. Jaworski, J, Kapitein LC, Gouveia SM, Dortland BR, Wulf PS, Grigoriev I, Camera P, Spangler SA, Di Stefano P, Demmers J, Krugers H, Defilippi P, Akhmanova A, et al. Dynamic microtubules regulate dendritic spine morphology and synaptic plasticity. Neuron. 2006; 61:85-100.

51. Palazzo AF, Eng CH, Schlaepfer DD, Marcantonio EE, Gundersen GG. Localized stabilization of microtubules by integrin- and FAK-facilitated Rho signaling. Science. 2004; 303:836-839.

52. Koch N, Kobler O, Thomas U, Qualmann B, Kessels MM. Terminal axonal arborization and synaptic bouton formation critically rely on abp1 and the arp2/3 complex. PLoS One. 2014; 9:e97692.

53. Mierke CT. The role of focal adhesion kinase in the regulation of cellular mechanical properties. Phys Biol. 2013; 10:065005.

54. Schaller MD. Cellular functions of FAK kinases: insight into molecular mechanisms and novel functions. J Cell Sci. 2010; 123:1007-1013.

55. Guan JL, Shalloway D. Regulation of focal adhesionassociated protein tyrosine kinase by both cellular adhesion and oncogenic transformation. Nature. 1992; 358:690-692.

56. Tancioni I, Miller NL, Uryu S, Lawson C, Jean C, Chen XL, Kleinschmidt EG, Schlaepfer DD. FAK activity protects nucleostemin in facilitating breast cancer spheroid and tumor growth. Breast Cancer Res. 2015; 17:47. 
57. Guan JL, Shalloway D. Regulation of focal adhesionassociated protein tyrosine kinase by both cellular adhesion and oncogenic transformation. Nature. 1992; 358:690-692.

58. Pylayeva Y, Gillen KM, Gerald W, Beggs HE, Reichardt LF, Giancotti FG. Ras- and PI3K-dependent breast tumorigenesis in mice and humans requires focal adhesion kinase signaling. J Clin Invest. 2009; 119:252-266.

59. Luo M, Fan H, Nagy T, Wei H, Wang C, Liu S, Wicha MS, Guan JL. Mammary epithelial-specific ablation of the focal adhesion kinase suppresses mammary tumorigenesis by affecting mammary cancer stem/progenitor cells. Cancer Res. 2009; 69:466-474.

60. Lahlou H, Sanguin-Gendreau V, Zuo D, Cardiff RD, McLean GW, Frame MC, Muller WJ. Mammary epithelialspecific disruption of the focal adhesion kinase blocks mammary tumor progression. Proc Natl Acad Sci USA. 2007; 104:20302-20307.

61. Provenzano PP, Inman DR, Eliceiri KW, Beggs HE, Keely PJ. Mammary epithelial-specific disruption of focal adhesion kinase retards tumor formation and metastasis in a transgenic mouse model of human breast cancer. Am J Pathol. 2008; 173:1551-1565.

62. Ribeiro A, Balasubramanian S, Hughes D, Vargo S, Powell EM, Leach JB. $\beta 1$-Integrin cytoskeletal signaling regulates sensory neuron response to matrix dimensionality. Neuroscience. 2013; 248:67-78.

63. Perdiz D, Mackeh R, Pous C, Baillet A. The ins and outs of tubulin acetylation: more than just a post-translational modification? Cell Signal. 2010; 23:763-771.

64. Wloga D, Gaertig J. Post-translational modifications of microtubules. J Cell Sci. 2010; 123:3447-3455.

65. Nolan L, Johnson PW, Ganesan A, Packham G, Crabb SJ. Will histone deacetylase inhibitors require combination with other agents to fulfil their therapeutic potential? Br J Cancer. 2008; 99:689-694.

66. Mai A, Altucci L. Epi-drugs to fight cancer: from chemistry to cancer treatment, the road ahead. Int J Biochem Cell Biol. 2009; 41:199-213.

67. Bonezzi K, Belotti D, North BJ, Ghilardi C, Borsotti P, Resovi A, Ubezio P, Riva A, Giavazzi R, Verdin E, Taraboletti G. Inhibition of SIRT2 potentiates the antimotility activity of taxanes: implications for antineoplastic combination therapies. Neoplasia. 2012; 14:846-854.
68. Umezawa Y, Kurosu T, Akiyama H, Wu N, Nogami A, Nagao T, Miura O. Down regulation of Chk1 by p53 plays a role in synergistic induction of apoptosis by chemotherapeutics and inhibitors for Jak2 or BCR/ABL in hematopoietic cells. Oncotarget. 2016; 7:44448-44461. doi: 10.18632/oncotarget.9844.

69. Liu F, Jia L, Wang P, Wang H, Farren TW, Agrawal SG. STAT3 and NF- $\kappa \mathrm{B}$ cooperatively control in vitro spontaneous apoptosis and poor chemo-responsiveness in patients with chronic lymphocytic leukemia. Oncotarget. 2016; 7:32031-32045. doi: 10.18632/oncotarget.8672.

70. Srinivas KP, Viji R, Dan VM, Sajitha IS, Prakash R, Rahul PV, Santhoshkumar TR, Lakshmi S, Pillai MR. DEPTOR promotes survival of cervical squamous cell carcinoma cells and its silencing induces apoptosis through downregulating PI3K/AKT and by up-regulating p38 MAP kinase. Oncotarget. 2016; 7:24154-24171. doi: 10.18632/ oncotarget.8131.

71. Cavalieri B, Mosca M, Ramadori P, Perrelli MG, De Simone L, Colotta F, Bertini R, Poli G, Cutrìn JC. Neutrophil recruitment in the reperfused-injured rat liver was effectively attenuated by repertaxin, a novel allosteric noncompetitive inhibitor of CXCL8 receptors: a therapeutic approach for the treatment of post-ischemic hepatic syndromes. Int $\mathrm{J}$ Immunopathol Pharmacol. 2005; 18:475-486.

72. La Rana G1, Russo R, D'Agostino G, Sasso O, Raso GM, Iacono A, Meli R, Piomelli D, Calignano A. AM404, an anandamide transport inhibitor, reduces plasma extravasation in a model of neuropathic pain in rat: role for cannabinoid receptors. Neuropharmacology. 2008; 54:521-529.

73. Choi Y, Yoon YW, Na HS, Kim SH, Chung JM. Behavioral signs of ongoing pain and cold allodynia in a rat model of neuropathic pain. Pain. 1994; 59:369-376.

74. Boland LM, Allen AC, Dingledine R. Inhibition by bradykinin of voltage-activated barium current in a rat dorsal root ganglion cell line: role of protein kinase C. J Neurosci. 1991; 11:1140-1149.

75. Platika D, Boulos MH, Baizer L, Fishman MC. Neuronal traits of clonal cell lines derived by fusion of dorsal root ganglia neurons with neuroblastoma cells. Proc Natl Acad Sci USA. 1985; 82:3499-3503. 